\title{
What Students Feel in School Influences the Strategies They Use for Learning: Academic Emotions and Cognitive/Meta-Cognitive Strategies
}

\author{
Ronnel B. King ${ }^{1}$ and Shaljan Areepattamannil ${ }^{2}$ \\ ${ }^{1}$ Learning Sciences Laboratory, National Institute of Education, Nanyang Technological University, Singapore \\ ${ }^{2}$ Office of Education Research, National Institute of Education, Nanyang Technological University, Singapore
}

\begin{abstract}
$\mathrm{T}$ he aim of this study was to investigate how academic emotions were related to cognitive and metacognitive strategy use. Secondary school students $(N=1,147)$ participated in this study and answered relevant questionnaires on academic emotions (enjoyment, hope, pride, anger, anxiety, shame, hopelessness, and boredom) and the use of various cognitive (elaboration, organisation, and rehearsal) and metacognitive strategies (planning, monitoring, regulating). Results of the analyses indicated that students who experienced positive emotions were more likely to use different types of cognitive and metacognitive strategies. Negative academic emotions were found to be non-significant predictors of strategy use. Implications are discussed.
\end{abstract}

Keywords: achievement emotions, academic emotions, control-value theory, cognitive strategies, metacognitive strategies

Students who use various cognitive and meta-cognitive strategies are more likely to learn the material, have higher academic performance, and acquire more positive learning outcomes compared to their counterparts who are not as proficient in using these strategies (for reviews see Winne, 2011; Zimmerman, 2011).

Numerous studies have investigated the predictors of cognitive and meta-cognitive strategy use. In general, antecedents identified in previous research have focused on cognitive-motivational constructs such as epistemological beliefs (e.g., Bromme, Pieschl, \& Stahl, 2010; Richter \& Schmid, 2010), self-related beliefs (e.g., Garcia \& Pintrich, 1994; Schunk \& Usher, 2011; Zimmerman, 2000), achievement goals (e.g., Wolters, 2004), task values (Battle \& Wigfield, 2003), and interest (e.g., Hidi \& Ainley, 2008) among others (for an overview see also Hodis, Meyer, McClure, Weir, \& Walkey, 2011; Walkey, McClure, Meyer, \& Weir, 2013; Wigfield, Klauda, \& Cambria, 2011). To date, scant attention has been paid to the role of emotions in facilitating or inhibiting the use of these strategies.

An exception would be the case of test anxiety, which has been well-studied in the literature (Zeidner, 1998, 2007). It is important to examine how a wider range of emotions influence cognitive and meta-cognitive strategy use given that students experience a whole gamut of emo- tions related to school aside from anxiety (Boekaerts, 2011; Efklides, 2006; Meyer \& Turner, 2002; Pekrun, 2009). For example, students may enjoy school, be hopeful about succeeding in a test, or experience pride in their schoolwork. Alternatively, they may also feel bored in class or hopeless about the prospect of passing an exam. How do these distinct emotions influence the use of various cognitive and metacognitive strategies? The aim of this study was to answer this question by examining whether academic emotions could predict the use of various cognitive and metacognitive strategies.

\section{Emotions}

Early studies in educational psychology have mostly treated emotions as outcome variables, such as in the attribution-affect link specified in attribution theory (Weiner, 1985). However, there is also some support for its role as an antecedent of motivated behaviour. For example, research on test anxiety has shown that anxious students worry about how well they will do in school, thus exerting a negative influence on memory and test performance (see Wigfield \& Eccles, 1989 for a review).

The role of emotions on learning is still hotly debated. Some researchers argue that positive emotions might be detrimental to the learning process. As Aspinwall (1998,

Address for correspondence: Dr Ronnel B. King, Learning Sciences Laboratory, National Institute of Education, NIE 5-B3-47, Nanyang Technological University, 1 Nanyang Walk, Singapore.Email: ronnel.king@nie.edu.sg 
p. 7) noted, 'our primary goal is to feel good, and feeling good makes us lazy thinkers who are oblivious to potentially useful negative information and unresponsive to meaningful variations in information and situation' These researchers claim that positive emotions can lead to unrealistic appraisals, facilitate superficial information processing, and decrease motivation to pursue challenging goals (Aspinwall, 1998).

Some laboratory-based studies support this contention. For example, experimental studies have shown that the induction of positive moods can lead people to: (a) illusively overestimate the probability of attaining positive outcomes and underestimate the probability of attaining negative outcomes; (b) undermine effortful exertion by letting them think that everything is already going well; (c) neglect the careful prevention of future obstacles because of the motivation to maintain the pleasant mood and ignore negative thoughts; and (d) reduce the cognitive resources available for the task on hand (Aspinwall, 1998).

However, other researchers disagree with this stance and argue that positive emotions can indeed be beneficial for learning and performance (e.g., Pekrun et al., 2002). Experimental research has also shown that positive mood can enhance divergent thinking, facilitate flexible problem-solving, and improve cognitive performance (Isen, Daubman, \& Nowicki, 1987). There is also some evidence showing the positive mood can facilitate elaborate information processing (Titz, 2001).

More recent research provides support for the latter argument (Pekrun et al., 2002). Correlational evidence has illustrated the benefits of positive affect especially when these emotions help the people focus on the task at hand. A problem with the former argument - which construes positive emotions as non-beneficial for task outcomes - is that the experiments these researchers cite may lack external validity. Usually, the mood-induction procedures focused a participant's attention on emotion-arousing stimuli such as pictures or recall of significant life events, thus less attention was available for the task at hand. This may be the case for test anxiety, where the student worries too much about the upcoming exam, thereby limiting the cognitive resources available for studying. However, if the emotion is focused on the learning task itself, the situation becomes different. Rather than being distracted, the attention can be directed towards the task on hand. An example would be the experience of enjoyment in studying, which may help students become so immersed in the task that even the perception of time and borders between the self and the external environment is diminished in consciousness (i.e., flow experiences; Csikszentmihalyi \& Csikszentmihalyi, 1988).

\section{Academic Emotions}

Emotions are multifaceted phenomena consisting of multiple component processes that include affective, cognitive, physiological, and behavioral elements (Damasio,
2004; Scherer, 2000). However, for this study the focus was on achievement emotions in general or academic emotions in particular.

Pekrun and colleagues (2002) developed the controlvalue theory of emotions as a framework to understand achievement emotions, which refer to emotions linked to achievement activities or achievement outcomes such as success or failure. As the focus was on the academic domain in this research, the term 'academic emotions' was used to denote the emotions related to academic learning and achievement.

Pekrun et al. (2002) proposed that emotions could be classified into: (1) positive activating emotions such as enjoyment, hope, and pride; (2) positive deactivating emotions such as relief; (3) negative activating emotions such as anger, anxiety, and shame; and (4) negative deactivating emotions such as boredom and hopelessness (see also Pekrun, 2006, 2009). In terms of valence, positive emotions can be differentiated from negative emotions such as pleasant enjoyment experienced during studying versus unpleasant anxiety felt before an upcoming exam. In terms of activation, physiologically activating emotions that facilitate excitement can be distinguished from deactivating emotions that induce relaxation. An example of such a distinction would be between activating anger that makes a student more physiologically aroused versus deactivating hopelessness that makes a student withdraw from the process.

Extant research has begun to map out the relationship of academic emotions to a wide range of educational outcomes. For example, Titz (2001) found that the positive emotions of enjoyment and hope were positively correlated with the use of elaboration strategies. The negative emotions of anger, anxiety, and boredom, on the other hand, were negatively related with elaboration. He also found enjoyment and hope to be positively correlated with effort, while anger, anxiety, and boredom were negatively correlated with them. Turner, Thorpe, and Meyer (1998) found that negative emotions were detrimental to the preference for difficult work.

Other researchers have found academic emotions to be linked with performance outcomes. For example, Pekrun, Elliot, and Maier (2009) found that positive activating emotions such as enjoyment, hope, and pride were positively related to students' midterm exam scores. On the other hand, negative emotions - both activating and deactivating (anger, anxiety, shame, hopelessness, and boredom) - were negatively related to midterm exam scores. Villavicencio and Bernardo (2013) found that enjoyment and pride were positive predictors of grades among undergraduate students (see also Villavicencio, 2011).

Academic emotions have also been linked to motivational orientations and effort exertion. The positive activating emotions of enjoyment, hope, and pride were found to be positively related to intrinsic motivation and effort in school, while the negative emotions of anger, anxiety, shame, hopelessness, and boredom were 
negatively related to intrinsic motivation and effort (Pekrun, Goetz, Frenzel, Barchfeld, \& Perry, 2011). Ouano (2011) found that intrinsic motivation was positively related to positive academic emotions and that extrinsic motivation was positively related to the negative emotions.

\section{Cultural Context}

Most studies on academic emotions have been conducted in the Western setting (e.g., Govaerts \& Gregoire, 2008). Cross-cultural psychologists have argued that the relationships among variables may change as a function of cultural context. Henrich, Heine, and Norenzayan (2010) criticised psychologists for overly relying on samples from WEIRD (Western, educated, industrialised, rich, democratic) societies and generalising these results to the rest of the world. Therefore, it is important to consider the issue of cross-cultural generalisability in this study.

Research on academic emotions in the Asian context in general and the Philippines in particular has been limited. The few existing studies have focused on validating the Academic Emotions Questionnaire (AEQ) developed by Pekrun and his colleagues. These studies have generally found support for the factor structure of the AEQ in various cultural contexts, including the Philippines (Frenzel, Thrash, Pekrun, \& Goetz, 2007; King, 2010; see also Tze, Daniels, Klassen, \& Li, 2013). Moreover, studies have also shown that the relationship of various academic emotions to outcome variables did not differ significantly from findings in Western cultures (e.g., Ouano, 2011; Villavicencio, 2011; Villavicencio \& Bernardo, 2013).

Despite these cross-cultural similarities, there is also evidence of cultural differences. A qualitative study conducted by Bernardo, Ouano, and Salanga (2009) found support for the generalisability of the common academic emotions examined by Pekrun and his colleagues among Filipino students. However, they also highlighted that Filipino students' academic emotions were broader than those typically examined in the Western research. In particular, Filipino students considered certain psychological phenomena as a type of academic emotion although Western research has not typically conceived of them as such.

Given the lack of concrete evidence for culture would modify the relationship between academic emotions and learning strategies, an agnostic stance was maintained in this study.

\section{The Present Study}

Extant research has suggested that academic emotions may be linked to various academic outcomes. However, a study that looks at how academic emotions are linked to a wide range of cognitive and meta-cognitive strategies is still lacking. The aim of this study is to examine the linkage between academic emotions and cognitive/meta-cognitive strategy use.

Based on previous studies showing the positive effects of positive academic emotions (Frenzel, Thrash, Pekrun,
\& Goetz, 2007; Goetz, Frenzel, Pekrun, Hall, \& Lüdtke, 2007; Pekrun, Goetz, Titz, \& Perry, 2002), it was hypothesised that positive academic emotions will have a positive association with various cognitive and meta-cognitive strategies (H1).

Given the negative association between negative academic emotions and a wide range of outcomes, it was hypothesised that negative academic emotions (both activating and deactivating) would be negative predictors of cognitive and metacognitive strategy use ( $\mathrm{H} 2)$.

\section{Methods \\ Participants}

The study involved 1,147 secondary school students (216 first-year students, 387 second-year students, 374 thirdyear students and 170 fourth-year students) from five different schools in Metro Manila, Philippines.

Four of these were private schools, while one was a public school. The private schools were all Catholic schools, had smaller class sizes, and catered to students from the middle income to upper income bracket. The public school was typical of the several public schools in the Metro Manila area. Compared to the private schools, it had a larger class size, and was non-sectarian. Students in the public school came from the lower to middle income bracket. All these four schools cater to students from first to fourth year and use English as the medium of instruction. There were 623 males and 524 females. The average age was 14.20 years old.

\section{Procedures}

The questionnaires were administered by the first author during class hours with the assistance of the classroom teachers. Students were informed that they can withdraw from the study at any time if they wished to do so.

\section{Instruments}

Academic emotions. The Short Version of the Academic Emotions Questionnaire for Filipinos (S-AEQ-F; King, 2010), which was based on the Academic Emotions Questionnaire for Learning (AEQ; Pekrun et al., 2011) was used. It comprises a total of 16 items, with each emotion being measured by 2 items. It has been previously validated among Filipino students using CFA (King, 2010; King \& Watkins, 2011). Academic emotions measured included the positive activating emotions of enjoyment (e.g., 'I look forward to studying'), hope (e.g., 'I feel optimistic that I will make good progress in studying'), and pride (e.g., 'I think I can be proud of my accomplishments at studying'); the negative activating emotions of anger (e.g., 'I get angry when I have to study'), anxiety (e.g., 'I get tense and nervous while studying'), shame (e.g., 'I feel ashamed because I am not as good as others in studying'); and the negative de-activating emotions of boredom (e.g., 'Studying is dull and monotonous'), and hopelessness (e.g., 'I feel hopeless when I think about studying'). 
Cognitive strategies. Three types of cognitive strategies drawn from the cognitive strategies subscale of the Goal Orientation and Learning Strategies Survey (GOALS-S; Dowson \& McInerney, 2004) were measured: elaboration (e.g., 'When learning things for school, I try to see how they fit together with other things I already know'), organising (e.g., 'I try to organise my school notes when I want to learn things for school'), and rehearsal (e.g., 'I reread my books when I want to learn things for school'). Each of the cognitive strategies were measured by six items.

Meta-cognitive strategies. Three types of meta-cognitive strategies drawn from GOALS-S (Dowson \& McInerney, 2004) were measured: monitoring (e.g., 'I often ask myself questions to see if I understand what I am learning'), planning (e.g., 'I often plan ahead so that I can do well in my schoolwork'), and regulating (e.g., 'When I don't understand something at school, I try to get someone to help me'). Each of the metacognitive strategies were measured by six items.

Higher scores indicated a greater degree of endorsement. Questionnaires were all administered in English as it was the medium of instruction for Filipino students from the elementary to the tertiary level.

\section{Data Analytic Strategy}

Given the hierarchical nature of the current dataset (i.e., students nested within schools), hierarchical linear modelling (HLM; Raudenbush \& Bryk, 2002) analyses were conducted using HLM 6 for Windows (Raudenbush, Bryk, Cheong, Congdon, \& du Toit, 2004).

First, fully unconditional models (i.e., null or intercept-only models) were fitted to partition the total variance in outcome measures into within-school variance (i.e., variance attributable to students) and between-school variance (i.e., variance attributable to schools). A fully unconditional model is analogous to a one-way random effects ANOVA model (Raudenbush \& Bryk, 2002). Finally, a full model that included both student- and school-level variables was estimated. Student-level predictors included the different types of academic emotions - enjoyment, hope, pride, anger, anxiety, shame, hopelessness, and boredom. We also included age and gender as covariates. For the school level, we included type of school (private school or public school) as a school-level predictor.

Restricted maximum likelihood was the method of estimation used. Dichotomous student- (e.g., gender) and school-level (e.g., type of school) variables were kept in their original metric. All continuous student-level variables were group-mean centred. Centring not only helps in the interpretation of the model parameters (Ferron et al., 2008), but also 'removes high correlations between random intercepts and slopes, and high correlations between first- and second-level variables and cross-level interactions' (Kreft \& de Leeuw, 1998, p. 114). The HLM mixed model equations are given in the Appendix.

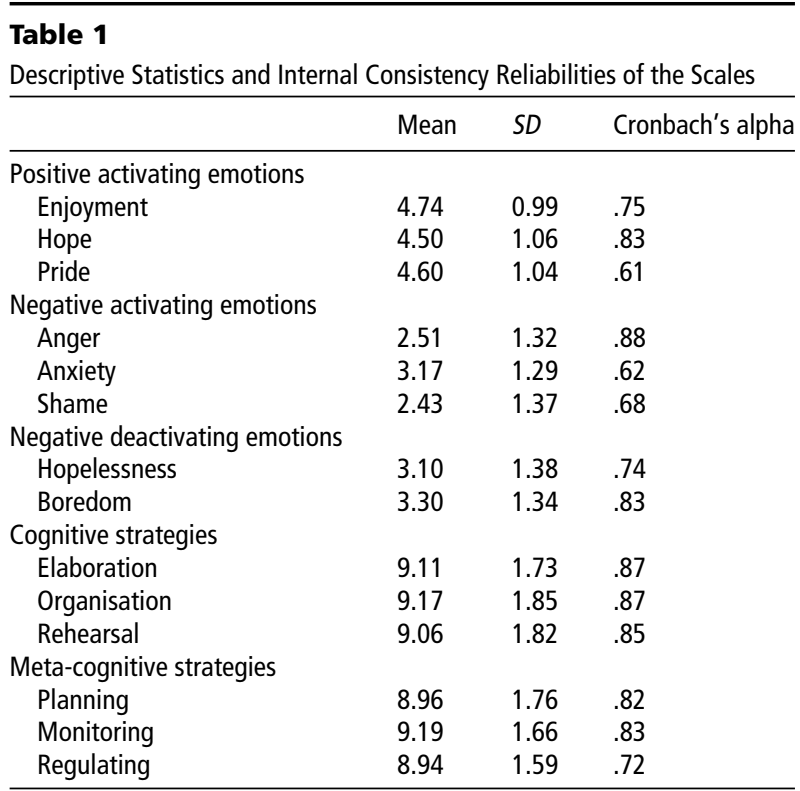

\section{Results \\ Preliminary Analyses}

Table 1 shows the descriptive statistics and internal consistency reliabilities of the various scales used in this study. Most of the scales had acceptable Cronbach's alpha reliabilities except for pride and anxiety scales had lower than ideal alpha estimates. Given that these constructs were only measured by two items each, it seems reasonable to expect that alphas obtained would be lower than ideal. It is usually the case that shorter versions of questionnaires (which is what was used in this study) have lower alphas compared to the full version of the questionnaire. In this study the pragmatic decision to use the short version of the scale was made given the time constraints imposed by the schools.

\section{Correlations Among the Variables}

Table 2 shows the bivariate correlations among the variables. The positive activating emotions of enjoyment, hope, and pride were all positively correlated with the various cognitive and meta-cognitive strategies, which were in line with theoretical expectations. Anger and boredom were both negatively associated with all the cognitive and meta-cognitive strategies. Anxiety had more ambiguous effects. It had weak positive correlations with rehearsal and monitoring. Hopelessness was not significantly associated with most of the cognitive and metacognitive strategies included in this study. For example, the correlations among the positive activating emotions of enjoyment, hope, and pride ranged from $r=.48$ to $r=.65(p<.001)$. However, they were not significantly correlated or negatively correlated with the negative activating and negative deactivating emotions. These correlations lend support to the classification of academic emotions proposed by 
Table 2

Bivariate Correlations Among the Variables

\begin{tabular}{|c|c|c|c|c|c|c|c|c|c|c|c|c|c|c|}
\hline & & 2 & 3 & 4 & 5 & 6 & 7 & 8 & 9 & 10 & 11 & 12 & 13 & 14 \\
\hline 1. Enjoyment & 1 & $.650 * * *$ & $.483^{* * *}$ & $-.306^{* * *}$ & -.013 & .022 & -.041 & $-.291^{* * *}$ & $.578^{* * *}$ & $.553^{* * *}$ & $.561^{* * *}$ & $.564^{* * *}$ & $.573^{* * *}$ & $.490 * * *$ \\
\hline 2. Hope & & - & $.540^{* * *}$ & $-.207^{* * *}$ & .011 & .022 & -.034 & $-.149^{* * *}$ & $.493^{* * *}$ & $.475^{* * *}$ & $.471^{* * *}$ & $.504^{* * *}$ & $.474^{* * *}$ & $.439 * * *$ \\
\hline 3. Pride & & & - & $-.133^{* * *}$ & .039 & .034 & -.032 & $-.145^{* * *}$ & $.414^{* * *}$ & $.406^{* * *}$ & $.391^{* * *}$ & $.418^{* * *}$ & $.418^{* * *}$ & $.368^{* * *}$ \\
\hline 4. Anger & & & & - & $.471^{* * *}$ & $.370^{* * *}$ & $.421^{* * *}$ & $.695^{* * *}$ & $-.228^{* * *}$ & $-.218^{* * *}$ & $-.217^{* * *}$ & $-.192^{* * *}$ & $-.208^{* * *}$ & $-.179^{* * *}$ \\
\hline 5. Anxiety & & & & & - & $.586^{* * *}$ & $.444^{* * *}$ & $.413^{* * *}$ & .032 & .020 & $.058^{*}$ & .030 & $.080^{* *}$ & $.052+$ \\
\hline 6. Shame & & & & & & - & $.528^{* * * *}$ & $.389 * * *$ & -.001 & .026 & $.054^{+}$ & .040 & .008 & .004 \\
\hline 7. Hopelessness & & & & & & & - & $.515^{* * *}$ & $-.060^{*}$ & -.005 & .029 & -.003 & -.029 & .007 \\
\hline 8. Boredom & & & & & & & & - & $-.234^{* * *}$ & $-.204^{* * *}$ & $-.169^{* * *}$ & $-.162^{* * *}$ & $-.213^{* * *}$ & $-.151^{* * *}$ \\
\hline 9. Elaboration & & & & & & & & & - & $.621^{* * *}$ & $.574^{* * *}$ & $.636 * * *$ & $.812^{* * *}$ & $.552^{* * *}$ \\
\hline 10. Organisation & & & & & & & & & & - & $.656^{* * *}$ & $.819^{* * *}$ & $.640^{* * *}$ & $.595^{* * *}$ \\
\hline 11. Rehearsal & & & & & & & & & & & - & $.677^{* * *}$ & $.616^{* * *}$ & $.705^{* * *}$ \\
\hline 12. Planning & & & & & & & & & & & & - & $.650^{* * *}$ & $.594^{* * *}$ \\
\hline 13. Monitoring & & & & & & & & & & & & & - & $.564^{* * *}$ \\
\hline 14. Regulating & & & & & & & & & & & & & & - \\
\hline
\end{tabular}

Note: ${ }^{+} p<.10,{ }^{*} p<.05,{ }^{* *} p<.01,{ }^{* * *} p<.001$

Pekrun et al. (2002). All the cognitive and metacognitive strategies were also moderately positively correlated with each other.

\section{Partitioning of Variance in Cognitive and Meta-Cognitive Strategies}

The intercept-only models (see Tables 3-4) indicated that students' scores on the various cognitive strategies, which included elaboration $\left(\gamma_{00}=8.98\right)$, organisation $\left(\gamma_{00}=\right.$ $8.98)$, and rehearsal $\left(\gamma_{00}=8.87\right)$, varied across the five schools: $\chi^{2}(4, N=1147)=67.58, p<.001 ; \chi^{2}(4, N=$ $1147)=74.47, p<.001 ; \chi^{2}(4, N=1147)=94.19, p<.001$ for elaboration, organisation, and rehearsal respectively. Moreover, for elaboration, $4 \%$ of the variance was between schools and $96 \%$ of the variance was within schools. For both organisation and rehearsal, $6 \%$ of the variance was between schools and $94 \%$ was within schools.

Next, we analysed the intercept-only models for students' meta-cognitive strategies. Results indicated that students' scores on the metacognitive strategies - planning $\left(\gamma_{00}=8.73\right)$, monitoring $\left(\gamma_{00}=9.03\right)$, and regulating $\left(\gamma_{00}=8.85\right)$ - varied across the five schools: $\chi^{2}(4, N$ $=1147)=112.57, p<.001 ; \chi^{2}(4, N=1147)=91.41$, $p<.001 ; \chi^{2}(4, N=1147)=31.42, p<.001$ for planning, monitoring, and regulating respectively. For planning, $8 \%$ of the variance was between schools and $92 \%$ was within schools. For monitoring, $6 \%$ of the variance was between schools and 94\% was within schools; while for regulating, $2 \%$ of the variance was between schools and $98 \%$ was within schools.

Tables 3 and 4 also present the results of the full model with both student-level and school-level predictors. Student-level predictors included the various types of academic emotions (enjoyment, hope, pride, anger, anxiety, shame, hopelessness, and boredom). Gender and age were also entered as predictors at the student level to control for their effects. For the school level, we included school type (private vs. public) as a predictor.
Results indicated that the positive academic emotions of enjoyment, hope, and pride were positive predictors of all the cognitive and meta-cognitive strategies. In general, the negative academic emotions of anger, shame, hopelessness, and boredom did not significantly predict the various strategies. An exception was anxiety, which was a weak positive predictor for some types of strategies such as elaboration, rehearsal, monitoring, and regulating.

\section{Discussion}

The aim of this study was to explore whether academic emotions were systematically related to students' cognitive and meta-cognitive strategy use. It was found that students who frequently experienced the positive emotions of enjoyment, hope, and pride were more likely to use various cognitive and meta-cognitive strategies, thus confirming the first hypothesis. These findings dovetail with previous research on academic emotions, which showed how positive activating emotions are related to optimal educational outcomes.

Recent studies in the field of positive psychology also corroborate the current findings about the benefits of experiencing positive emotions. Although not focusing specifically on emotions felt in school but on emotions in general, Fredrickson's $(1998,2001)$ broaden and build theory argues that the frequent experience of positive emotions can broaden people's thoughts and behaviours and facilitate more adaptive responses to the environment. The experience of the positive activating emotions of enjoyment, hope, and pride in school may have helped the students broaden their cognitive repertoires, as evinced in their use of various cognitive and metacognitive strategies.

The second hypothesis was not confirmed. In general, most of the negative academic emotions were not significant predictors of cognitive/metacognitive strategy used in the regression model. There were also a certain degree of difference between the different types of 
Table 3

Results of Hierarchical Linear Modeling Analyses Predicting Cognitive Strategies

\begin{tabular}{|c|c|c|c|c|c|c|c|c|c|c|c|c|}
\hline & \multicolumn{4}{|c|}{ Elaboration } & \multicolumn{4}{|c|}{ Organisation } & \multicolumn{4}{|c|}{ Rehearsal } \\
\hline & \multicolumn{2}{|c|}{$\begin{array}{l}\text { Unconditional } \\
\text { model }\end{array}$} & \multicolumn{2}{|c|}{$\begin{array}{l}\text { Full } \\
\text { model }\end{array}$} & \multicolumn{2}{|c|}{$\begin{array}{l}\text { Unconditional } \\
\text { model }\end{array}$} & \multicolumn{2}{|c|}{$\begin{array}{c}\text { Full } \\
\text { model }\end{array}$} & \multicolumn{2}{|c|}{$\begin{array}{l}\text { Unconditional } \\
\text { model }\end{array}$} & \multicolumn{2}{|c|}{$\begin{array}{l}\text { Full } \\
\text { model }\end{array}$} \\
\hline & $B$ & $S E$ & $B$ & $S E$ & $B$ & $S E$ & $B$ & $S E$ & $B$ & SE & $B$ & $S E$ \\
\hline Intercept & $8.98^{* * * *}$ & 0.17 & $8.92^{* * *}$ & .16 & $8.98 * * *$ & .19 & $8.52^{* * *}$ & .21 & $8.87^{* * *}$ & .19 & $8.60^{* * *}$ & .18 \\
\hline \multicolumn{13}{|l|}{ Level-1 } \\
\hline Gender (Female) & & & .03 & .10 & & & $.31 * * *$ & .09 & & & $.18^{*}$ & .09 \\
\hline Age & & & -.04 & .04 & & & -.06 & .04 & & & -.02 & .04 \\
\hline Enjoyment & & & $.61^{* * *}$ & .07 & & & $.66^{* * *}$ & .06 & & & $.69^{* * *}$ & .06 \\
\hline Hope & & & $.24^{* * *}$ & .07 & & & $.26^{* * *}$ & .06 & & & $.24^{* * *}$ & .06 \\
\hline Pride & & & $.20 * * *$ & .06 & & & $.25^{* * *}$ & .05 & & & .20 & $.05^{* * *}$ \\
\hline Anger & & & -.07 & .06 & & & -.07 & .05 & & & $-.13^{* *}$ & .05 \\
\hline Anxiety & & & $.16^{* *}$ & .05 & & & .05 & .05 & & & $.11^{*}$ & .04 \\
\hline Shame & & & -.07 & .05 & & & .00 & .04 & & & .00 & .04 \\
\hline Hopelessness & & & .03 & .05 & & & .08 & .04 & & & .07 & .04 \\
\hline Boredom & & & -.10 & .05 & & & .07 & .05 & & & .01 & .05 \\
\hline \multicolumn{13}{|l|}{ Level-2 } \\
\hline School type (Public) & & & $.86^{*}$ & .15 & & & .74 & .38 & & & .89 & .29 \\
\hline Intercept variance $\left(\tau_{00}\right)$ & 0.17 & & 0.10 & & .20 & & .11 & & .21 & & .06 & \\
\hline Level 1 variance $\left(\sigma^{2}\right)$ & 3.61 & & 2.73 & & 3.26 & & 2.20 & & 3.11 & & 2.13 & \\
\hline Intraclass correlation $(\rho)$ & .04 & & .00 & & .06 & & .05 & & .06 & & .03 & \\
\hline \multicolumn{13}{|l|}{ Variance in cognitive strategies } \\
\hline between schools explained (\%) & NA & & 93 & & NA & & 46 & & NA & & 72 & \\
\hline \multicolumn{13}{|l|}{ Variance in cognitive strategies } \\
\hline within schools explained (\%) & NA & & 24 & & NA & & 32 & & NA & & 31 & \\
\hline
\end{tabular}

Note: Unstandardised coefficients are shown; $N_{\text {level } 1}=1,147$ students; $N_{\text {level } 2}=$ five schools; ${ }^{*} p<.05,{ }^{* *} p<.01,{ }^{* * *} p<.001$.

Table 4

Results of Hierarchical Linear Modeling Analyses Predicting Meta-cognitive Strategies

\begin{tabular}{|c|c|c|c|c|c|c|c|c|c|c|c|c|}
\hline & \multicolumn{4}{|c|}{ Planning } & \multicolumn{4}{|c|}{ Monitoring } & \multicolumn{4}{|c|}{ Regulating } \\
\hline & \multicolumn{2}{|c|}{$\begin{array}{l}\text { Unconditional } \\
\text { model }\end{array}$} & \multicolumn{2}{|c|}{$\begin{array}{l}\text { Full } \\
\text { model }\end{array}$} & \multicolumn{2}{|c|}{$\begin{array}{l}\text { Unconditional } \\
\text { model }\end{array}$} & \multicolumn{2}{|c|}{$\begin{array}{c}\text { Full } \\
\text { model }\end{array}$} & \multicolumn{2}{|c|}{$\begin{array}{l}\text { Unconditional } \\
\text { model }\end{array}$} & \multicolumn{2}{|c|}{$\begin{array}{l}\text { Full } \\
\text { model }\end{array}$} \\
\hline & $B$ & $S E$ & $B$ & $S E$ & $B$ & SE & $B$ & SE & $B$ & SE & $B$ & SE \\
\hline Intercept & $8.73^{* * *}$ & .21 & $8.63^{* * *}$ & .21 & $9.03^{* * *}$ & .18 & $8.79 * * *$ & .16 & $8.85^{* * *}$ & .11 & $8.71^{* * *}$ & .15 \\
\hline \multicolumn{13}{|l|}{ Level-1 } \\
\hline Gender (Female) & & & .06 & .09 & & & .16 & .08 & & & .09 & .08 \\
\hline Age & & & -.05 & .03 & & & .03 & .03 & & & .03 & .03 \\
\hline Enjoyment & & & $.60^{* * *}$ & .06 & & & $.65^{* * *}$ & .06 & & & $.50 * * *$ & .06 \\
\hline Hope & & & $.30 * * *$ & .05 & & & $.20 * * *$ & .05 & & & $.24 * * *$ & .05 \\
\hline Pride & & & $.23^{* * *}$ & .05 & & & $.22^{* * *}$ & .05 & & & $.19^{* * *}$ & .05 \\
\hline Anger & & & -.06 & .05 & & & -.03 & .04 & & & $-10^{*}$ & .05 \\
\hline Anxiety & & & .05 & .04 & & & $.19^{* * *}$ & .04 & & & $.12_{* *}$ & .04 \\
\hline Shame & & & .01 & .04 & & & -.07 & .04 & & & $-.08^{*}$ & .04 \\
\hline Hopelessness & & & .02 & .04 & & & .01 & .04 & & & .07 & .04 \\
\hline Boredom & & & -.01 & .05 & & & -.07 & .04 & & & -.01 & .04 \\
\hline \multicolumn{13}{|l|}{ Level-2 } \\
\hline School type (Public) & & & .91 & .40 & & & .80 & .27 & & & .44 & .20 \\
\hline Intercept variance $\left(\tau_{00}\right)$ & .26 & & .12 & & .18 & & .05 & & .06 & & .03 & \\
\hline Level 1 variance $\left(\sigma^{2}\right)$ & 2.89 & & 1.97 & & 2.60 & & 1.71 & & 2.47 & & 1.82 & \\
\hline Intraclass correlation $(\rho)$ & .08 & & .06 & & .06 & & .03 & & .02 & & .01 & \\
\hline \multicolumn{13}{|l|}{ Variance in cognitive strategies } \\
\hline between schools explained (\%) & NA & & 52 & & NA & & 71 & & NA & & 55 & \\
\hline \multicolumn{13}{|l|}{ Variance in cognitive strategies } \\
\hline within schools explained (\%) & NA & & 32 & & NA & & 34 & & NA & & 27 & \\
\hline
\end{tabular}

Note: Unstandardised coefficients are shown; $N_{\text {level } 1}=1147$ students, $N_{\text {level } 2}=$ five schools; ${ }^{*} p<.05,{ }^{* *} p<.01,{ }^{* * *} p<.001$.

academic emotions and how they related to strategy use. For example, anxiety was found to be a positive predictor of certain types of strategies. On the other hand, boredom and anger were negatively correlated with all the strategies.
It seems surprising that anxiety can positively predict the use of several types of cognitive and metacognitive strategies. However, it is possible that anxiety can also motivate certain types of students to use different strategies in their learning. For example, certain types of students 
may be highly anxious and yet also get high GPAs. Their anxiety might actually impel them to study harder and use various types of strategies so that they can cope with the exams. It is possible that a certain degree of anxiety might actually be helpful and it is the more severe types of anxiety that could be debilitating.

This study also showed the negative association of boredom and anger to all the strategies examined. Teachers and educators may need to pay special attention to curbing the onset of these two types of emotions in the school context. Boredom is especially harmful because it might make students tune out of school. Anger might also lead to other externalising aggressive behaviours, which may have detrimental consequences for learning.

The regression analysis showed that when all the emotions are included in the model, only positive activating emotions are highly significant. The other negative emotions mostly become non-significant. This shows the greater predictive power of positive emotions. This has important implications for practitioners who want to harness the power of positive emotions to facilitate student learning. While this study was strictly correlational and could not shed light on causal relations, studies using experimental designs lend support to the current conclusions. These experimental studies have generally shown positive emotions to be related to better learning (Bryan \& Bryan, 1991; Bryan, Mathur, \& Sullivan, 1996). For example, Bryan and Bryan (1991) induced positive emotions among students and asked them to solve math problems. Compared to those in the control condition, those who were in the positive emotions condition solved more math problems and had higher math self-efficacy. The current study adds to this growing literature by showing that positive emotions are also positively related to a broad range of cognitive and metacognitive strategies.

\section{Limitations and Directions for Future Research}

A limitation of this study was its cross-sectional design, which cannot reveal causal connections. Future research using longitudinal or experimental designs could be adopted. It is also likely that the relationships among academic emotions and the various cognitive and metacognitive strategies may be linked by reciprocal causation (Pekrun \& Stephens, 2009). Thus, studies using crosslagged designs that look at the reciprocal links between strategies and emotions across time may be helpful in revealing their dynamic relationships.

Another weakness is the exclusive reliance on selfreport data, which is known to be affected by common method variance and social desirability issues (Fulmer \& Frijters, 2009; Samueltstuen \& Braten, 2007). While some researchers criticise the use of self-report in measuring cognitive and metacognitive strategy use (e.g., Winne \& Jamieson-Noel, 2002), in this article the tradition of Pintrich and his colleagues, who used self-report questionnaires to measure strategy use, was followed (e.g., Pintrich,
Smith, Garcia, \& McKeachie, 1993). Despite their weaknesses, self-report questionnaires are easy to use, suitable for large-scale surveys, and have the ability to tap into respondents' beliefs and self-perceptions about their own learning processes (Perry \& Winne, 2006; Pintrich, 2004; Zimmerman, 2008). However, it is acknowledged that future research should consider complementing self-reports with other types of data collection methods, such as the use of online measures of learning strategy use (Vandevelde, van Keer, \& Rosseel, 2013).

Third, only emotions tied to the school context were measured. Future studies may consider measuring more general types of emotions that may have a spillover effect on the more specific academic emotions. Fourth, students' tendencies to give socially desirable responses were not measured. Social desirability may influence the results obtained and it is recommended that future studies measure social desirability responding. Fourth, we only conducted a quantitative study. It might be useful in future research to conduct a mixed-methods study that includes a qualitative component to investigate whether Filipino students' understanding of learning strategies and academic emotions are concordant with Western theorising. It is also recommended that future studies consider the inclusion of possible moderators.

\section{Conclusion}

In general, this study showed the importance of taking academic emotions into account when investigating student learning. With few exceptions, such as test anxiety research (Zeidner, 1998; 2007), the study of emotions in school has been relatively neglected, although this has been changing in recent years (e.g., Boekaerts, 2011; Efklides, 2006; Meyer \& Turner, 2002; Pekrun et al., 2002). This study found that academic emotions are closely related to students' cognitive and metacognitive strategy use. As the use of these strategies are hallmarks of successful learning, researchers and practitioners need to take into account their students' emotional experiences in school in order to harness the power of these emotions to facilitate better learning.

\section{Appendix \\ HLM Mixed Model Equations}

\section{Null Models}

$E{ }^{\prime} A B O R A T I O N_{i j}=\gamma_{00}+u_{0 j}+r_{i j}$

ORGANIZING $G_{i j}=\gamma_{00}+u_{0 j}+r_{i j}$

REHEARSAL $L_{i j}=\gamma_{00}+u_{0 j}+r_{i j}$

$P L A N N I N G_{i j}=\gamma_{00}+u_{0 j}+r_{i j}$

$M O N I T O R I N G_{i j}=\gamma_{00}+u_{0 j}+r_{i j}$

REGULATING $i j=\gamma_{00}+u_{0 j}+r_{i j}$

\section{Full Models}

ELABORATION $_{i j}=\gamma_{00}+\gamma_{01}{ }^{*}$ PRIVATEPUBLIC $j+$

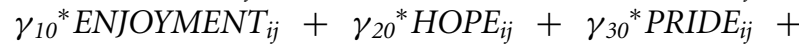
$\gamma_{40}{ }^{*} A_{N G E R_{i j}}+\gamma_{50}{ }^{*}{ }{ }^{* N X I E T Y} Y_{i j}+\gamma_{60}{ }^{*}$ SHAME $_{i j}+$ 
$\gamma_{70}{ }^{*}$HOPELESS $_{i j}+\gamma_{80}{ }^{*}$ BOREDOM $_{i j}+\gamma_{90}{ }^{*} A G E_{i j}+$ $\gamma_{100}{ }^{*} G E N D E R_{i j}+u_{0 j}+r_{i j}$

ORGANIZING $_{i j}=\gamma_{00}+\gamma_{01}{ }^{*}$ PRIVATEPUBLIC $_{j}+$

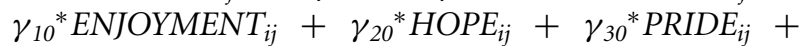

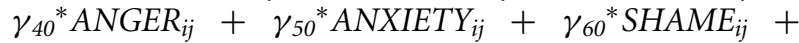

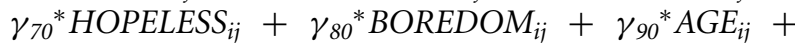
$\gamma_{100}{ }^{*} G E N D E R_{i j}+u_{0 j}+r_{i j}$

REHEARSAL $_{i j}=\gamma_{00}+\gamma_{01}{ }^{*}$ PRIVATEPUBLIC $C_{j}+$ $\gamma_{10}{ }^{*}$ ENJOYMENT $_{i j}+\gamma_{20}{ }^{*}$ HOPE $_{i j}+\gamma_{30}{ }^{*}$ PRIDE $_{i j}+$

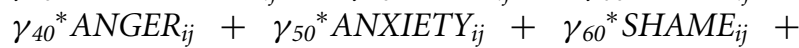
$\gamma_{70}{ }^{*}$ HOPELESS $_{i j}+\gamma_{80}{ }^{*}$ BOREDOM $_{i j}+\gamma_{90}{ }^{*} A G E_{i j}+$ $\gamma_{100}{ }^{*}$ GENDER $_{i j}+u_{0 j}+r_{i j}$

PLANNING $_{i j}=\gamma_{00}+\gamma_{01}{ }^{*}$ PRIVATEPUBLIC $_{j}+$ $\gamma_{10}{ }^{*} E N J O Y M E N T_{i j}+\gamma_{20}{ }^{*}{ }{ }_{10 P E} E_{i j}+\gamma_{30}{ }^{*} P^{*} I D E_{i j}+$

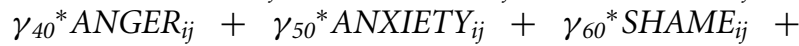
$\gamma_{70}{ }^{*}$HOPELESS $_{i j}+\gamma_{80}{ }^{*}$ BOREDOM $_{i j}+\gamma_{90}{ }^{*} A G E_{i j}+$ $\gamma_{100}{ }^{*} G E N D E R_{i j}+u_{0 j}+r_{i j}$

MONITORING $_{i j}=\gamma_{00}+\gamma_{01}{ }^{*}$ PRIVATEPUBLIC $j+$

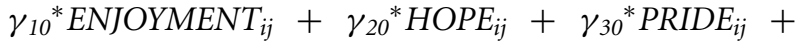
$\gamma_{40}{ }^{*}$ ANGER $i j+\gamma_{50}{ }^{*}{ }{ }^{* N X I E T Y}{ }_{i j}+\gamma_{60}{ }^{*}$ SHAME $_{i j}+$ $\gamma_{70}{ }^{*}$ HOPELESS $_{i j}+\gamma_{80}{ }^{*}$ BOREDOM $_{i j}+\gamma_{90}{ }^{*} A G E_{i j}+$ $\gamma_{100}{ }^{*} G E N D E R_{i j}+u_{0 j}+r_{i j}$

REGULATING $_{i j}=\gamma_{00}+\gamma_{01}{ }^{*}$ PRIVATEPUBLIC $C_{j}+$ $\gamma_{10}{ }^{*}$ ENJOYMENT $_{i j}+\gamma_{20}{ }^{*}{ }{ } O P E_{i j}+\gamma_{30}{ }^{*}$ PRIDE $_{i j}+$

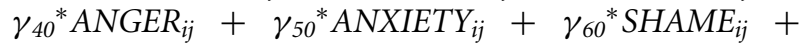
$\gamma_{70}{ }^{*}$ HOPELESS $_{i j}+\gamma_{80}{ }^{*}$ BOREDOM $_{i j}+\gamma_{90}{ }^{*} A G E_{i j}+$ $\gamma_{100}{ }^{*} G E N D E R_{i j}+u_{0 j}+r_{i j}$

\section{References}

Aspinwall, L.G. (1998). Rethinking the role of positive affect in self-regulation. Motivation and Emotion, 22, 1-32.

Battle, A., \& Wigfield, A. (2003). College women's value orientations toward family, career, and graduate school. Journal of Vocational Behavior, 62, 56-75.

Bernardo, A.B.I., Ouano, J., \& Salanga, M.G.C. (2009). What is an academic emotion? Insights from Filipino bilingual students' emotion words associated with learning. Psychological Studies, 54, 28-37.

Boekaerts, M. (2011). Emotions, emotion regulation, and selfregulation of learning. In B.J. Zimmerman \& D.H. Schunk (Eds.), Handbook of self-regulation of learning and performance (pp. 408-425). New York: Routledge.

Bromme, R., Pieschl, S., \& Stahl, E. (2010). Epistemological beliefs are standards for adaptive learning: A functional theory about epistemological beliefs and metacognition. Metacognition and Learning, 5, 7-26.

Bryan, T., \& Bryan, J. (1991). Positive mood and math performance. Journal of Learning Disabilities, 24, 490-494.

Bryan, T., Mathur, S., \& Sullivan, K. (1996). The impact of positive mood on learning. Learning Disability Quarterly, 19, 153-162.
Csikszentmihalyi, M., \& Csikszentmihalyi, I.S. (1988). Optimal experience: Psychological studies of flow in consciousness. Cambridge, UK: Cambridge University Press.

Damasio, A.R. (2004). Emotions and feelings: A neurobiological perspective. In A.S.R. Manstead, N. Frijda, \& A. Fischer (Eds.), Feelings and emotions (pp. 49-57). Cambridge, UK: Cambridge University Press.

Dowson, M., \& McInerney, D.M. (2004). The development and validation of the Goal Orientation and Learning Strategies Survey (GOALS-S). Educational and Psychological Measurement, 64, 290-310.

Efklides, A. (2006). Metacognition and affect: What can metacogntive experiences tell us about the learning process? Educational Research Review, 1, 3-14.

Ferron, J.M., Hogarty, K.Y., Dedrik, R.F., Hess, M.R., Niles, J.D., \& Kromrey, J.D. (2008). Reporting results from multilevel analyses. In A. O'Connell \& D.B. McCoach (Eds.), Multilevel modeling of educational data (pp. 391-426). Charlotte, NC: Information Age Publishing.

Fredrickson, B.L. (1998). What good are positive emotions? Review of General Psychology, 2, 300-319.

Fredrickson, B.L. (2001). The role of positive emotions in positive psychology: The broaden-and-build theory of positive emotions. American Psychologist, 58, 218-226.

Frenzel, A.C., Thrash, T.M., Pekrun, R., \& Goetz, T. (2007). Achievement emotions in Germany and China: A cross-cultural validation of the Academic Emotions Questionnaire-Mathematics (AEQ-M). Journal of CrossCultural Psychology, 38, 302-309.

Fulmer, S.M., \& Frijters, J.C. (2009). A review of self-report and alternative approaches in the measurement of student motivation. Educational Psychology Review, 21, 219246.

Garcia, T., \& Pintrich, P.R. (1994). Regulating motivation and cognition in the classroom: The role of self-schemas and self-regulatory strategies. In D.H. Schunk, \& B.J. Zimmerman (Eds.), Self-regulation of learning and performance: Issues and educational applications (pp. 127-153). Hillsdale, NJ: Lawrence Erlbaum.

Goetz, T., Frenzel, A.C., Pekrun, R., Hall, N.C., \& Lüdtke, O. (2007). Between- and within-domain relations of students' academic emotions. Journal of Educational Psychology, 99, $715-733$.

Govaerts, S., \& Gregoire, J. (2008). Development and construct validation of an Academic Emotions Scale. International Journal of Testing, 8, 34-54.

Henrich, J., Heine, S.J., \& Norenzayan, A. (2010). Most people are not WEIRD. Nature, 466, 29.

Hidi, S., \& Ainley, M. (2008). Interest and self-regulation: Relationships between two variables that influence learning. In D.H. Schunk \& B.J. Zimmerman (Eds.), Motivation and selfregulated learning: Theory, research, and application (pp. 77109). New York: Erlbaum.

Hodis, F.A., Meyer, L.H., McClure, J., Weir, K.F., \& Walkey, F.H. (2011). A longitudinal investigation of motivation and secondary school achievement using growth mixture modeling. Journal of Educational Psychology, 103, 312-323. 
Isen, A.M., Daubman, K.A., \& Nowicki, G.P. (1987). Positive affect facilitates creative problem solving. Journal of Personality and Social Psychology, 52, 1122-1131.

King, R.B., \& Watkins, D.A. (2011). The reliability and validity of the Goal Orientation and Learning Strategies Survey (GOALS-S): A Filipino investigation. The Asia Pacific Education Researcher, 20, 579-594.

King, R.B. (2010). What do students feel in school and how do we measure them?: Examining the psychometric properties of the S-AEQ-F. Philippine Journal of Psychology, 43, 161-176.

Kreft, I., \& de Leeuw, J. (1998). Introducing multilevel modelling. Newbury Park, CA: Sage.

Meyer, D.K., \& Turner, J.C. (2002). Discovering emotion in classroom motivation research. Educational Psychologist, 37, 107114.

Ouano, J.A. (2011). Motivational antecedents of academic emotions in Filipino college students. The Asia-Pacific Education Researcher, 20, 127-132.

Pekrun, R. (2006). The control-value theory of achievement emotions: Assumptions, corollaries, and implications for educational research and practice. Educational Psychology Review, 18, 315-341.

Pekrun, R. (2009). Global and local perspectives on human affect: Implications of the control-value theory of achievement emotions. In M. Wosnitza, S.A. Karabenick, A. Efklides, \& P. Nenninger (Eds.), Contemporary motivation research (pp. 97-115). Cambridge, MA: Hogrefe.

Pekrun, R., Elliot, A.J., \& Maier, M.A. (2009). Achievement goals and achievement emotions: Testing a model of their joint relations with academic performance. Journal of Educational Psychology, 101, 115-135.

Pekrun, R., Goetz, T., Frenzel, A.C., Barchfeld, P., \& Perry, R.P. (2011). Measuring emotions in students' learning and performance: The Achievement Emotions Questionnaire (AEQ). Contemporary Educational Psychology, 36, 36-48.

Pekrun, R., Goetz, T., Titz, W., \& Perry, R.P. (2002). Academic emotions in students' self-regulated learning and achievement: A program of quantitative and qualitative research. Educational Psychologist, 37, 91-106.

Pekrun, R., \& Stephens, E. J. (2009). Goals, emotions, and emotion regulation: Perspectives of the control-value theory: Commentary on Tyson, Linnenbrink-Garcia, and Hill. Human Development, 52, 357-365.

Perry, N., \& Winne, P. (2006). Learning from learning kits: Study traces students' self-regulated engagements with computerized content. Educational Psychology Review, 18, 211-228.

Pintrich, P.R. (2004). A conceptual framework for assessing motivation and self-regulated learning in college students. Educational Psychology Review, 16, 385-407.

Pintrich, P.R., Smith, D.A.F., Garcia, T., \& Mckeachie, W.J. (1993). Reliability and predictive validity of the Motivated Strategies for Learning Questionnaire (MSLQ). Educational and Psychological Measurement, 53, 801-813.

Raudenbush, S.W., \& Bryk, A.S. (2002). Hierarchical linear models: Applications and data analysis methods. Newbury Park, CA: Sage.
Raudenbush, S.W., Bryk, A.S., Cheong, Y.F., Congdon, R., \& du Toit, M. (2004). HLM 6: Hierchical linear and nonlinear modeling. Lincolnwood, IL: Scientific Software International.

Richter, T., \& Schmid, S. (2010). Epistemological beliefs and epistemic strategies in self-regulated learning. Metacognition and Learning, 5, 47-65.

Scherer, K.R. (1984). On the nature and function of emotion: A component process approach. In K.R. Scherer \& P. Ekman (Eds.), Approaches to emotion (pp. 293-317). Hillsdale, NJ: Erlbaum.

Schunk, D.H., \& Usher, E.L. (2011). Assessing self-efficacy for self-regulated learning. In B.J. Zimmerman \& D.H. Schunk (Eds.), Handbook of self-regulation of learning and performance (pp. 282-297). New York: Routledge.

Titz, W. (2001). Emotionen von Studierenden in Lernsituationen [University students' emotions at learning]. Münster, Germany: Waxmann.

Turner, J.C., Thorpe, P.K., \& Meyer, D.K. (1998). Students' reports of motivation and negative affect: A theoretical and empirical analysis. Journal of Educational Psychology, 90, 758771.

Tze, V.M.C., Daniels, L.M., Klassen, R.M., \& Li, J.C.-H. (2013). Canadian and Chinese university students' approaches to coping with academic boredom. Learning and Individual Differences, 23, 32-43.

Vandevelde, S., van Keer, H., \& Rosseel, Y. (2013). Measuring the complexity of upper primary school children's self-regulated learning: A multi-component approach. Learning and Individual Differences, 38, 407-425.

Villavicencio, F.T. (2011). Critical thinking, negative academic emotions, and achievement: A mediational analysis. The Asia-Pacific Education Researcher, 20, 118-126.

Villavicencio, F.T., \& Bernardo, A.B.I. (2013). Positive academic emotions moderate the relationship between self-regulation and academic achievement. British Journal of Educational Psychology, 83, 329-340.

Weiner, B. (1985). An attributional theory of achievement motivation and emotion. Psychological Review, 92, 548-573.

Walkey, F.H., McClure, J., Meyer, L.H., \& Weir, K.F. (2013). Low expectations equal no expectations: Aspirations, motivation, and achievement in secondary school. Contemporary Educational Psychology, 38, 306-315.

Wigfield, A., \& Eccles, J. (1989). Test anxiety in elementary and secondary school students. Educational Psychologist, 24, 159183.

Wigfield, A., Klauda, S.L., \& Cambria, J. (2011). Influences on the development of academic self-regulatory processes. In B.J. Zimmerman \& D.H. Schunk (Eds.), Handbook of selfregulation of learning and performance (pp. 33-48). New York: Routledge.

Winne, P.H. (2011). A cognitive and metacognitive analysis of self-regulated learning. In B.J. Zimmerman \& D.H. Schunk (Eds.), Handbook of self-regulation of learning and performance (pp. 15-32). New York: Routledge.

Winne, P.H., \& Jamieson-Noel, D. (2002). Exploring students' calibration of self reports about study tactics and 
achievement. Contemporary Educational Psychology, 27, 551572.

Wolters, C. A. (2004). Advancing achievement goal theory: Using goal structures and goal orientations to predict students' motivation, cognition, and achievement. Journal of Educational Psychology, 96, 236-250.

Zeidner, M. (1998). Test anxiety: The state of the art. New York: Plenum.

Zeidner, M. (2007). Test anxiety in educational contexts: Concepts, findings, and future directions. In P.A. Schutz \& R. Pekrun (Eds.), Emotion in education (pp. 165-184). San Diego, CA: Academic Press
Zimmerman, B.J. (2000). Self-efficacy: An essential motive to learn. Contemporary Educational Psychology, 24, 8291.

Zimmerman, B.J. (2008). Investigating self-regulation and motivation: Historical background, methodological developments, and future prospects. American Educational Research Journal, 45, 166-183.

Zimmerman, B.J. (2011). Motivational sources and outcomes of self-regulated learning and performance. In B.J. Zimmerman \& D.H. Schunk (Eds.), Handbook of self-regulation of learning and performance (pp. 49-64). New York: Routledge. 